\title{
Importance of incorporating measures of attitude in planning and evaluating nursing education
}

\author{
Barbara J. Daly ${ }^{* 1,2}$, Nora Nock ${ }^{2}$, Seunghee Margevicius ${ }^{2}$, Neal J. Meropol ${ }^{3,4}$ \\ ${ }^{1}$ School of Nursing, Case Western Reserve University, United States \\ ${ }^{2}$ School of Medicine, Case Western Reserve University, United States \\ ${ }^{3}$ Case Comprehensive Cancer Center, School of Medicine, Case Western Reserve University, United States \\ ${ }^{4}$ Research Oncology, Flatiron Health, United States
}

Received: October 9, 2018

DOI: $10.5430 /$ jnep.v9n4p1
Accepted: November 22, $2018 \quad$ Online Published: November 26, 2018

URL: https://doi.org/10.5430/jnep.v9n4p1

\begin{abstract}
Learners' attitudes towards a topic or behavior has long been recognized as an important component in the evaluation of formal education as well as in achieving desired behavior change. However, attitudes are frequently neglected and evaluation of outcomes from continuing nursing education often includes only changes in knowledge and learner satisfaction. We describe measurement of attitudes of oncology nurses towards holding discussions with patients about the option of participating in a clinical trial, in comparison to what can be learned from measuring knowledge alone. This article illustrates important insights that can be gained through inclusion of measures of attitude in both designing and evaluating continuing education using data from a larger on-going study.
\end{abstract}

Key Words: Continuing education evaluation, Nurse attitudes, Outcomes of nursing continuing education

\section{INTRODUCTION}

In 1956, Benjamin Bloom published the first edition of his comprehensive framework for classifying learning objectives and outcomes. ${ }^{[1]}$ Focusing initially on the levels in the cognitive domain (knowledge, comprehension, application, analysis, synthesis, evaluation), he also included levels of psychomotor skill and the affective, or attitudinal domain. While Bloom's full taxonomy has been widely used for decades in curricular design and evaluation in nursing schools, application of the psychomotor and affective domains are less well incorporated in continuing education. The overemphasis on increases in knowledge, to the neglect of attitudinal measures, has been noted particularly in nursing education. ${ }^{[2]}$
Evaluation of the outcomes of continuing education (CE) in nursing has focused to a large extent on post-tests that reflect the learner's own perception of learning and satisfaction with the educational offering, despite long-standing recognition of the need for objective measures of both knowledge and attitude. While there has been increasing emphasis among health professions on outcomes, increasingly required by continuing education certification bodies, a recent review noted continuing reliance in nursing $\mathrm{CE}$ on the learners' own evaluation of perceptions about the educational program. ${ }^{[4,5]}$

The importance of attitudes as a determinant of learning and subsequent behavior is well established and reflected in widely tested theories of behavior change, such as Ajzen \& Fishbein's Theory of Planned Behavior ${ }^{[6]}$ and the Health

\footnotetext{
* Correspondence: Barbara J. Daly; Email: barbara.daly@ case.edu; Address: School of Nursing and School of Medicine, Case Western Reserve University, United States.
} 
Belief Model. ${ }^{[7]}$ However, less attention has been paid to incorporating pre- and post-measures of attitudes, possibly reflecting an assumption that greater understanding of a topic related to desired behavior will be associated with more positive attitudes. Formal inclusion of attitudinal factors in both designing continuing educational offerings and evaluating the outcomes of education is particularly important for behaviors for which both a substantial knowledge base and positive attitudes towards the behavior are critical.

Discussing participation in cancer clinical trial with patients is a behavior that requires the nurse to have an adequate fund of knowledge about the conduct of trials and the ethical principles guiding research. In addition, however, a positive attitude towards both the role of the nurse in educating and discussing possible trial participation and towards trials in general is also essential. Clinical trials (CT) are the cornerstone of advances in cancer care and offer patients the opportunity for early access to treatments that are hoped to offer improved survival and reduced burdens. ${ }^{[8]}$ Nevertheless, fewer than $5 \%$ of patients actually enroll in trials. There are a variety of factors thought to explain the low participation rates, including lack of understanding of benefits and risks, concerns about side effects, and misunderstanding regarding the conduct of trials. ${ }^{[9-11]}$ Nurses, given their trusted role as patient advocates and the greater amount of time spent with patients, could be influential in addressing these issues and assuring patients are provided with needed education to support informed decisions. However, little is known about how nurses view their role in initiating general discussions of trials or proactively offering education to patients.

As part of testing of a web-based educational program for practicing oncology nurses, we obtained baseline data about both the pre-intervention knowledge about clinical trials and the attitudes of participating nurses towards clinical trials and their role in talking with their patients about the option of enrolling in a trial. The purpose of this article is to illustrate important insights that can be gained through inclusion of measures of attitude in continuing nursing education. We will describe data from the larger on-going study of the webbased program, focusing here on the baseline knowledge and attitudes of oncology nurses.

\section{MethodS}

The full study from which these data are drawn is a randomized trial of a web-based educational program. The data presented here represent a descriptive analysis of the baseline data only. Our aims in this article are to describe the insights gained from measures of baseline attitudes of practicing oncology nurses regarding the nurse's role in discussing clinical trials with patients.

\subsection{Participants}

The primary sample for this study was recruited using the Oncology Nursing Society (ONS) membership data base. Letters introducing the study were sent to all members, followed by e-mail invitations. Attendees at the 2017 ONS Congress were also solicited in person at the conference. Finally, in order to assure adequate representation from minority populations, we also advertised the study in the Minority Nurse newsletter. Participants were awarded 2 hours of continuing education credit if they participated in the entire program, as well as an entry in drawings for gift cards and iPads.

Nurses who responded to the invitation were eligible if they were engaged in active practice, full or part-time, and had direct contact with cancer patients. Respondents were ineligible if they were employed as clinical trial nurses, research coordinators, drug or device representatives, or were working in hospice.

\subsection{Procedures}

The web-based program in which participants enrolled tested a video educational program designed to both increase the participants' knowledge about trials and to address barriers (practical and attitudinal) to discussing trials with patients. In the intervention arm, responses to baseline surveys about the nurse's knowledge of clinical trials and human subjects regulations and about their attitude toward trials in general and specifically towards the role of the nurse in discussing trials with patients were used to tailor the educational videos that were then shown to the participant. A control group was provided non-tailored, on-screen written educational material covering the same topics.

When potential participants logged in to the web site, they were first asked to read and indicate informed consent to participate in the project, as approved by the study site's Institutional Review Board. All participants then were instructed to answer a series of baseline questions to provide demographic data and establish eligibility. All those eligible (intervention and control) then were instructed to complete the surveys which are the basis of this report.

\subsection{Measures}

In addition to the demographic questionnaire, all participants completed a test of their knowledge about clinical trials and a survey exploring their attitudes towards clinical trials in general and specifically towards the nurse's role in discussing trials with the patient. The demographic questionnaire included questions about the nurse's practice (number of patients with whom he/she had previously discussed CT), previous education about CT, availability of CT at work, and any personal experience with CT (self or family). 
Following the approach to measuring attitudes recommended by Francis et al., ${ }^{[14]}$ respondents first were asked three direct questions about fundamental attitudes towards the behavior of discussing trials with their patients: (1) how appropriate (or inappropriate) the nurse believed this would be, (2) how comfortable (or uncomfortable) the nurse would be in doing this, and (3) how ethical (or unethical) the nurse thought the behavior would be. The questions all used a 7 point Likert scale, anchored at one end by the most positive view and at the other end by the most negative view. The survey then presented 21 statements about specific beliefs that were posited to be the foundation or "indirect" reasons behind the "direct" attitude. The study team developed the questions from a preliminary qualitative study done with practicing oncology nurses about their views and relevant barriers to discussing CT with their patients. ${ }^{[15]}$ Each statement addressed potential positive outcomes of discussing trials or potential negative consequences or barriers. All questions began with the phrasing, "Discussing clinical trials will..." or "If I discuss CT with my patients, then..." Responses were made on a 7 point scale anchored at "Strongly disagree" and "Strongly agree". The three direct questions were analyzed individually. Indirect questions were reversed coded as needed in data entry in order to have a consistent metric of positive vs negative attitudes, with higher numbers indicating more positive attitudes.

The knowledge test was developed by the investigators from a previous study of patient knowledge and understanding of CT, modified to be appropriate for nurses. ${ }^{[12]}$ The original version was adapted from a test of a National Cancer Institute patient education booklet. ${ }^{[13]}$ It was composed of 21 statements about CT, with response options of agree, disagree, and unsure. For analysis purposes, each response was then coded as "correct" or "incorrect", including "unsure" in the incorrect category. The knowledge test addressed aspects of trial design and participation (11 questions), human subject protection regulations and principles (4 questions), and purposes and characteristics of the various phases of trials (6 questions).

\section{Results}

As can be seen in Table 1, the total sample was composed of 1,964 nurses. The great majority (97\%) were female, Caucasian $(87 \%)$, and had a bachelors or higher degree (80\%). Although $81 \%$ indicated that CT were available at their place of employment, only one-third rated themselves as either "extremely familiar" (7\%) or "very familiar" $(28 \%)$ with trials. Consistent with this, the reported frequency with which the majority (79\%) had held recent discussions with patients about trials was low, occurring with only 0-2 of their last 10 patients.

Table 1. Characteristics of nurse participants

\begin{tabular}{|c|c|}
\hline Characteristic & M (SD/Range) \\
\hline Age & $46.5(11.24 / 23-69)$ \\
\hline \multirow{2}{*}{ Yrs experience in oncology } & $15.1(9.9 / 1-45)$ \\
\hline & $\mathrm{N}(\%)$ \\
\hline Gender: Female & $1,912(97.4)$ \\
\hline \multicolumn{2}{|l|}{ Marital status } \\
\hline Married & $1,443(73.6)$ \\
\hline Not married & $518(26.4)$ \\
\hline \multicolumn{2}{|l|}{ Race } \\
\hline White & $1,707(87.0)$ \\
\hline Black & $52(2.7)$ \\
\hline Asian & $102(5.2)$ \\
\hline Other & $100(5.1)$ \\
\hline \multicolumn{2}{|l|}{ Highest degree } \\
\hline Diploma & $89(4.5)$ \\
\hline Associate & $303(15.4)$ \\
\hline Bachelors & $1,060(54.0)$ \\
\hline Masters & $476(24.3)$ \\
\hline DNP or PhD & $35(1.8)$ \\
\hline \multicolumn{2}{|l|}{ Primary work setting } \\
\hline Outpatient & $1,465(74.6)$ \\
\hline In-patient & $499(25.4)$ \\
\hline \multicolumn{2}{|c|}{$\%$ of time spent in direct PT care } \\
\hline $50 \%$ or less & $270(13.7)$ \\
\hline$>50 \%$ & $1,694(86.25)$ \\
\hline \multicolumn{2}{|c|}{ Familiarity with clinical trials } \\
\hline Extremely & $136(6.9)$ \\
\hline Very familiar & $548(27.9)$ \\
\hline Somewhat & $1,177(59.9)$ \\
\hline Not at all & $103(5.2)$ \\
\hline \multicolumn{2}{|c|}{ Received education on clinical trials } \\
\hline Yes & $1,546(78.7)$ \\
\hline No & $418(21.3)$ \\
\hline \multicolumn{2}{|c|}{ Clinical trials available at work } \\
\hline Yes & $1,588(80.9)$ \\
\hline No & $295(15.0)$ \\
\hline Don't know & $81(4.1)$ \\
\hline \multicolumn{2}{|c|}{ Have friends/family participated in CT } \\
\hline Yes & $536(27.3)$ \\
\hline No & $1,427(72.7)$ \\
\hline \multicolumn{2}{|c|}{ Number of PTs with whom you have discussed CT in past 3 month } \\
\hline 0 & $560(28.5)$ \\
\hline $1-5$ & $838(42.7)$ \\
\hline $6-10$ & 254 (12.9) \\
\hline $11-15$ & $122(6.2)$ \\
\hline $16-20$ & $78(4.0)$ \\
\hline$>20$ & $111(5.7)$ \\
\hline \multicolumn{2}{|c|}{ Of last 10 patients you cared for, with how many did you discuss CT } \\
\hline 0 & $875(44.6)$ \\
\hline $1-2$ & $679(34.6)$ \\
\hline 3-4 & $197(10.0)$ \\
\hline $5-6$ & $91(4.6)$ \\
\hline 7-8 & $51(2.6)$ \\
\hline $9-10$ & $68(3.4)$ \\
\hline
\end{tabular}

\subsection{Attitude}

To measure attitudes, participants were asked to respond to items on a 1 to 7 scale, with higher scores indicating more 
positive attitudes. As shown in Table 2, the mean score for "appropriate" was 6.36 (SD 1.13), the mean for "comfortable" was 5.15 (SD = 1.66), and the mean for "ethical" was 6.36 $(\mathrm{SD}=1.10)$. The mean for the total of 21 indirect items was 102.0 (range 42-147, SD = 15.64). The issues reflecting the most positive attitudes were reflected in strong disagreement to the items "I am discouraged from discussing CT with patients because the patient might seek care elsewhere" and
"Discussing CT with patients who have not exhausted all available standard therapies will result in worse health outcomes." The weakest positive (i.e. most negative) attitudes were "If I bring up CT patients will think I want them to participate" and "Discussing CT with patients will fit within the time I have to complete my work" (see Table 2). The scale was found to have good internal consistency reliability, with Cronbach's $\alpha$ of 0.87 .

Table 2. Attitude questions

\begin{tabular}{|c|c|}
\hline ITEM & $\begin{array}{l}\text { MEAN } \\
\text { SCORE* }\end{array}$ \\
\hline \multicolumn{2}{|l|}{ DIRECT ITEMS } \\
\hline Discussing CTs with patients is inappropriate & 6.36 \\
\hline Discussing CTs with patients is uncomfortable & 5.14 \\
\hline Discussing CTs with patients is unethical & 6.36 \\
\hline \multicolumn{2}{|l|}{ INDIRECT ITEMS } \\
\hline If I discuss CTs with patients, I am doing something positive for them & 5.15 \\
\hline Discussing information about CTs will give some patients unrealistic hope for recovery & 5.04 \\
\hline Discussing information about CTs will help patients ask the physician questions about treatment options & 5.60 \\
\hline If I discuss CTs with patients, I will get some for the facts wrong & 4.46 \\
\hline Discussing information about CTs will fit within the time I have to compete my work & 3.96 \\
\hline If I discuss CTs with patients, they will think they are being asked to be "guinea pigs" & 4.62 \\
\hline Discussing CTs with patients who have not exhausted all available standard therapies will result in worse health outcomes & 5.77 \\
\hline If I discuss CTs with patients, they will become upset & 5.33 \\
\hline Discussing information about CTs with patients will introduce them to riskier treatment options & 5.41 \\
\hline Discussing CTs with patients will encourage more of them to participate & 5.12 \\
\hline If I discuss clinical trials with patients, I will ease their concerns about receiving a placebo & 4.24 \\
\hline $\begin{array}{l}\text { Discussing basic information about CTs with patients will ease their concerns about having a computer choose their treatment } \\
\text { instead of a doctor (random assignment) }\end{array}$ & 4.22 \\
\hline CTs are good for the patients who participate & 4.92 \\
\hline I am concerned that CTs are too expensive for patient & 4.85 \\
\hline CTs are too burdensome for patients & 4.65 \\
\hline If I bring up CTs, patients will think their treatments are not working & 4.31 \\
\hline If I bring up CTs, patient will think I want them to participate & 3.93 \\
\hline If I bring up CTs, I may add to conflict that may exist between patients and their family members about treatment options & 4.29 \\
\hline Discussing CTs with patients may encourage them to go elsewhere for their care & 5.27 \\
\hline My interactions with patients are too limited to feel comfortable discussing CTs with them & 4.88 \\
\hline I am discouraged from discussing CTs because the patient might seek care elsewhere & 6.03 \\
\hline
\end{tabular}

*Items rated on a 1 to 7 scale, with 1 = strong disagreement and 7 = strong agreement. Items reflecting a negative attitude were reversed scored. Higher averages indicate more positive attitudes (i.e. strong agreement with positive items or strong disagreement with negative items)

\subsection{Knowledge}

Table 3 displays the 21 knowledge questions and percent of respondents who answered each question correctly. Scores ranged from 2 to 21 and average total correct percentage was $14.71(70 \%)$. The four questions about research ethics and human subjects protections were answered correctly by more than $88 \%$ of respondents. The five questions with the smallest percent of correct responses all addressed characteristics and purposes of the different phases of CT. The Cronbach's alpha was acceptable at 0.70 .

4

\section{Discussion AND CONCLUSION}

The potential role of clinical nurses as educators and facilitators for patients considering enrollment in clinical trials has been recognized by the Oncology Nursing Society as well as oncology clinicians. ${ }^{[16]}$ There have been a number of investigations of knowledge and skills of nurses employed as clinical trial nurses or coordinators, but less is known about the role of other oncology nurses, particularly staff nurses. ${ }^{[8,17,18]}$ 
Table 3. Knowledge test

\begin{tabular}{|c|c|}
\hline QUESTION & \% correct \\
\hline 1. Informed consent means that a patient is given information so he or she can freely decide whether to participate & 95.7 \\
\hline 2. Standard treatments are the most effective treatments currently known for cancer & 54.0 \\
\hline 3. Data and Safety Monitoring Boards are responsible for ensuring all risks are minimized for patients & 79.4 \\
\hline 4. It is up to the patient to decide whether to take part in a clinical trial & 96.1 \\
\hline 5. Clinical trials always involve more laboratory testing and medical appointments than standard treatments & 50.1 \\
\hline 6. If a patient takes part in a clinical trial, he or she could decide to stop participating at any time & 98.3 \\
\hline 7. Randomization means that treatment will be chosen by chance & 88,2 \\
\hline $\begin{array}{l}\text { 8. Both the standard of care and trial-related costs of participating in a clinical trial are always covered by a patient's } \\
\text { insurance company }\end{array}$ & 75.6 \\
\hline 9. Most cancer clinical trials involve a placebo & 60.1 \\
\hline 10. Side effects in clinical trials are usually worse than with standard treatments & 86.4 \\
\hline 11. Clinical trials are only available to patients after all standard treatments fail & 87.4 \\
\hline 12. The only way to find out about clinical trials is from a doctor & 93.4 \\
\hline 13. Phase III trials use randomization to assign patients to treatment and control groups & 50.2 \\
\hline 14. Phase I trials usually involve patients with a cancer that does not respond to standard treatment & 45.3 \\
\hline 15. Institutional Review Boards must approve ALL clinical trials before they may be offered to patients & 88.4 \\
\hline $\begin{array}{l}\text { 16. Prevention clinical trials can involve people at risk for cancer as well as people who have had cancer and are at risk } \\
\text { of recurrence }\end{array}$ & 72.1 \\
\hline 17. The main purpose of phase I trials is to test the effectiveness of new cancer treatments & 39.1 \\
\hline 18. The main purpose of phase III trials is to compare a new treatment against standard treatments & 71.8 \\
\hline 19. Phase I trials typically have $50-100$ patients & 25.9 \\
\hline 20. The main purpose of a clinical trial protocol is to describe how the study will be conducted & 78.6 \\
\hline 21. Phase II trials are conducted to find out what dosage is safe & 25.8 \\
\hline
\end{tabular}

The very high level of positive responses to the three direct attitude questions, in comparison to the somewhat lower level of positive responses to indirect questions (102 out of a potential 147) indicates that, although the nurse respondents believed that discussing trials with patients was appropriate, ethical, and comfortable, other more specific beliefs and perceptions would likely present barriers to the desired behavior. For example, despite believing that a behavior was appropriate and ethical, if the nurse perceived that he/she did not have enough time to add this activity to a busy schedule, the behavior would be unlikely to occur. Similarly, the belief that "If I bring up the subject of CTs then patients will believe I want them to participate" could make the nurse hesitant about raising the topic, despite having very accurate knowledge about CT.

Getz noted the overall willingness of nurses to refer patients to trials, but a relatively low rate of actual referral, associated with lack of confidence in discussing trials with patients. ${ }^{[19]}$ In his on-line study using a healthcare media data base, nurses in out-patient practices, presumably having more experience with trials compared to nurses working in in-patient areas, were more likely than hospital nurses to refer. Haugen et al reported on a nurse-led initiative to increase enrollment in cancer control/quality of life protocols in pediatric oncology and documented the significant increase in enrollment associated with nurse leadership of the initiatives. ${ }^{[20]}$ Both of these studies support the hypothesis that affective factors, such as familiarity and the influence of important role models can affect intention and behavior.

The results of the knowledge assessment, in themselves, do have some implications for nurse educators. The very high scores on the questions related to human subject protections suggest that the nurses in this sample were relatively well informed about critical aspects of research ethics, particularly informed consent and voluntariness. Thus, this content area would not be a high priority to address in educational programming or to use as a measure of learning. The comparatively lower level of understanding of the precise differences between the various phases of trials, such as the typical number of patients enrolled, is perhaps less important or significant to the behavior of discussing trials, but could be a target for education. As can be noted, however, the results of the knowledge test alone do not provide any guidance for educators regarding influential affective factors, such as 
ambivalence about the effect on patients of raising the topic of clinical trials or worry about approval from physicians.

Nurse engagement in discussing potential trial opportunities and providing education to patients about $\mathrm{CT}$ is a behavior that requires both knowledge and a generally positive attitude towards this role. Lack of knowledge about clinical trials can limit the nurse's ability to hold discussions, but ambivalence or actual negative attitudes towards clinical trials themselves, research in general, or the role of the nurse in initiating the topic of CT can be even more powerful influences. Thus, educational interventions that are designed and evaluated only in regard to knowledge gaps may be ineffective in actually increasing desired behavioral outcomes. This points to the need to include content or learning experiences in continuing education that are specifically targeted to address the modifiable beliefs and perceptions that are components of attitude.

In the parent trial from which these data were obtained, we addressed the potential attitudinal barriers in a number of ways. For example, role playing videos were used to portray how to fit CT discussions in to the normal work day, printed resources were identified that could be provided to patients so that the nurse did not have to rely solely on his/her own knowledge, and an endorsement from an officer of the professional association was included to reinforce the formal role expectation from influential nurse leadership.

Increasing knowledge of facts and developing higher level abilities to synthesize and evaluate will continue to be appropriate and important objectives of continuing education programs. However, to the extent that the ultimate objective of educational offerings in nursing is to contribute to changes in practice, our study illustrates the value of incorporating measures of attitude in devising objectives and learning strategies. This requires familiarity with the likely barriers and facilitators to the desired behaviors, as well as a measurement approach that will be sensitive to change following the educational offering.

\section{CONFLiCTS OF InTEREST Disclosure}

The authors declare that there is no conflict of interest.

\section{REFERENCES}

[1] Bloom BS.Taxonomy of Educational Objectives. New York: David McKay Company; 1956.

[2] Cazzell M, Rodriguez A. Qualitative analysis of student beliefs and attitudes after an objective structured clinical evaluation: Implications for affective domain learning in undergraduate nursing education. J Nurs Educ. 2011; 50(12): 711-714. PMid:22007712 https://doi.org/10.3928/01484834-20111017-04

[3] Gosnell .J. Evaluating continuing nursing education. J Cont Educ Nurs. 1984; 15(1): 9-11. PMid:6418776

[4] Davis D. Continuing education, guideline implementation, and the emerging transdisciplinary field of knowledge translation. J Cont Educ Health Prof. 2006; 26 (1): 5-12. PMid:16557510 https : //doi.org/10.1002/chp.46

[5] Griscti O, Jacono J. Effectiveness of continuing education programmes in nursing: literature review. J Adv Nurs. 2006; 55 (4): 449456. PMid:16866840 https ://doi.org/10.1111/j.1365-264 8.2006.03940.x

[6] Ajzen N, Fishbein M. Attitude-behavior relations: A theoretical analysis and review of empirical research. Psych Bull. 1977; 84(5): 888-918. https://doi.org/10.1037/0033-2909.84.5.888

[7] Janz NK, Becker, MH. The health belief model: A decade later. Health Educ Quart. 1984; 11(1): 1-47. PMid:6392204 https: //doi.org/10.1177/109019818401100101

[8] Ness EA, Royce C. Clinical trials and the role of the oncology clinical trials nurse. Nurs Clin N Am. 2017; 52: 133-148. PMid:28189159 https://doi.org/10.1016/j.cnur.2016.10.005

[9] Wright J, Whelan J, Schif S, et al. Why cancer patients enter randomized clinical trials: Exploring factors that influence their decisions. J Clin Onc. 2004; 22: 4312-18. PMid:15514372 https: //doi.org/10.1200/JC0.2004.01.187
[10] Mills EJ, Seely D, Rachlis B, et al. Barriers to participation in clinical trials of cancer: a meta-analysis and systematic review of patient-reported factors. Lancet Oncol. 2006; 7: 141-48. https : //doi.org/10.1016/S1470-2045(06) 70576-9

[11] Meropol N, Wong Y, Albrecht T, et al. Randomized Trial of a WebBased Intervention to Address Barriers to Clinical Trials. J Clin Oncol. 2016; 34(5): 469-478. PMid:26700123 https : //doi.org/ 10.1200/JC0.2015.63.2257

[12] Manne S, Kashy D, Albrecht T, et al. Knowledge, attitudes, and self-efficacy as predictors of preparedness for oncology clinical trials: a mediational model. Med Decis Making. 2014; 34: 454-463.PMid:24246567 https : //doi .org/10.1177/0272989X 13511704

[13] Davis SW, Nealon EO, Stone JC. Evaluation of the National Cancer Institute's clinical trials booklet. J Natl Cancer Inst Monogr. 1993; 14: 139-45.

[14] Francis JJ, Eccles MP, Johnston M, et al. Constructing Questionnaires Based on the Theory of Planned Behavior: A Manual for Health Services Researchers. University of Newcastle, Newcastle upon Tyne, United Kingdom, 2004.

[15] Flocke SA, Antognoli E, Daly BJ, et al. The role of oncology nurses in discussing clinical trials. Onc Nurs Forum. 2017; 44(5): 547-52. PMid:28820515 https : //doi.org/10.1188/17. ONF . 547-552

[16] Gaguski ME, George K, Bruce SD, et al. Oncology nurse generalist competencies: Oncology Nursing Society's Initiative to Establish Best Practice. Clin J Onc Nurs. 2017; 21(6): 1-9.

[17] Scott K, White K, Johnson C, et al. Knowledge and skills of cancer clinical trials nurses in Australia. J Adv Nurs. 2012; 68(5): 1111 1121. PMid:21950690 https ://doi .org/10.1111/j.1365-264 8.2011.05816. $\mathrm{x}$

[18] VanHoff D, Hesser T, Kelly KP, et al. Facilitating accrual to cancer control and supportive care trials: the clinical research asso- 
ciate perspective. BMC Med Res Method. 2013; 13: 154-161. PMid:24380578 https://doi.org/10.1186/1471-2288-13-1 54

[19] Getz KA. Examining and enabling the role of health care providers as patient engagement facilitators in clinical trials. Clin Ther. 2017;
39(11): 2203-2213. PMid:29079388 https://doi.org/10.101 6/j.clinthera.2017.09.014

[20] Haugen M, Kelly K, Leonard M, et al. Nurse-led programs to facilitate enrollment to children's oncology group cancer control trials. J Pediatr Oncol Nurs. 2016; 33(5): 387-391. PMid:26611754 https://doi.org/10.1177/1043454215617458 